\title{
Oligarquía concejil y patrimonio comunal: el proceso de perpetuación de las suertes en Daroca (siglos XVI-XVII)
}

\author{
José Antonio Mateos Royo
}

Las relaciones entre la propiedad no privada de la tierra y el aparato político durante la Época Moderna han sido objeto de reflexión histórica en los últimos años. La acción de la Corona vendría determinada por una creciente presión fiscal a partir de fines del siglo XVI y durante buena parte del XVII ${ }^{1}$. Su necesidad de dinero condicionaría un debilitamiento de las extensiones de uso común. De forma directa, mediante procesos como las venta de tierras baldías - cuyas consecuencias han suscitado opiniones contrapuestas ${ }^{2}$ - o la de señoríos. De manera indirecta, por el hecho de que los servicios en dinero y hombres, conjugada con otros recursos utilizados por la monarquía para obtener dinero -como las ventas de oficios o las de exenciones jurisdiccionales-, ocasiona un debilitamiento de las haciendas concejiles que les impondría el arrendamiento a particulares de usos anteriormente comunes cuando no la simple pignoración de los mismos.

A las actuaciones del Estado se uniría un comportamiento similar de las oligarquías locales ${ }^{3}$. La extensión de las propiedades señoriales sobre

\footnotetext{
1 Véase al respecto Garcia SANZ, A., «Bienes y derechos comunales. El proceso de privatización en Castilla durante los siglos XVI y XVII: El caso de tierras de Segovia", Hispania, (Madrid), 144, (1980), págs. 95-127; BERNAL, A.M., "Haciendas locales y tierras de propios: funcionalidad económica de los patrimonios municipales (siglos XVI-XIX)", en Hacienda Pública Española. Madrid, 55, (1978), págs. 285-312. Véase también Domínguez OrTiz, A., «La venta de cargos y oficios públicos en Castilla y sus consecuencias económicas y sociales", en Instituciones y sociedad en la España de los Austrias. Barcelona, Ariel, 1985, págs. 145-155.

2 Véase al respecto LÓPEZ-SALAZAR, J., Estructuras agrarias y sociedad rural en la Mancha (siglos XVI-XVII). Ciudad Real, Diputación Provincial, 1986, págs. 152-156; VASSBERG, D.E., Tierra y sociedad en Castilla. Barcelona, Crítica, 1986 y La venta de tierras baldías. El comunitarismo agrario en la corona de Castilla durainte el siglo XVI. Madrid, Ministerio de Agricultura, Pesca y Alimentación, 1983 y YUN CASALILLA, B., Sobre la transición al capitalismo en Castilla. Economia y sociedad en Tierra de Campos (1500-1830). Salamanca, Junta de Castilla y León, 1987, págs. 285-306.

3 Véase la nota 1.
} 
despoblados y la privatización de bienes comunales sitos en señoríos recién adquiridos a la Corona se darían la mano con la rapiña de quienes administraban los bienes concejiles para promover una concentración de la riqueza agraria en manos de estas oligarquías y un afianzamiento de los estamentos privilegiados. El proceso de oligarquización constatado en los municipios para el siglo XVII se hace corresponder con un ataque decidido por parte de los sectores dirigentes a bienes de propios y tierras comunales que vincularía importantes extensiones de terreno al dominio privado y los apartaría del aprovechamiento como bien común.

Si bien este proceso se da, los estudios por lo general descuidan una caracterización precisa de las zonas objeto de apropiación y los derechos comunales existentes sobre ellas, así como la existencia de posibles pactos sociales. En el ámbito del municipio, principal garante de la propiedad comunal, se tiende a poner el énfasis como motivo desencadenante de los ataques contra ésta en el mayor acaparamiento de poder y cerrazón interna por la minoría dirigente en el seno del Concejo, así como en el papel desempeñado en este proceso por la monarquía a través de las ventas de oficios en la Corona de Castilla y del mecanismo insaculatorio en la de Aragón. Sin embargo, se descuida en mucho mayor grado el papel jugado por el sentir vecinal, las costumbres comunales y las relaciones contractuales que determinaban en villas y lugares el acceso por la población a estos bienes comunes.

La presente aportación se orienta, por tanto, a subsanar en la medida de lo posible esta laguna a través de un estudio local centrado en Daroca, una pequeña ciudad de realengo sita en el medio rural aragonés. Ciudad de frontera dotada de fuero de repoblación, inserta en una Comunidad de aldeas de considerable extensión y ubicada en un territorio en que la presencia nobiliaria es poco importante, Daroca dispone de una serie de condiciones favorables para la existencia de fuertes tradiciones comunales sobre el aprovechamiento del suelo. El análisis comparado de su evolución con la de su concejo permitirá esclarecer sus relaciones intrínsecas así como el margen de control que los vecinos de la ciudad disponían respecto al uso de sus comunales.

\section{EL CONCEJO Y SUEVOLUCIÓN}

En Daroca, la política concejil durante los siglos XVI y XVII supone la culminación de un largo proceso, iniciado ya durante la Baja Edad Media y generalizado para toda Europa occidental. A lo largo del mismo, la configuración del Concejo como fuerza rectora de los intereses del común de vecinos va pareja a una oligarquización creciente en su seno. El municipio darocense revela una tendencia a ser controlado por una oligarquía urba- 
na, cada vez mejor configurada, formada por aquel sector de ciudadanos dotado de mayor prestigio social y poder económico.

Esta oligarquía vendrá definida en Daroca durante la Baja Edad Media por los caballeros, hombres libres de categoría no noble, poseedores de armas y caballo propio. La disposición por este estrato social de un nivel de rentas superior al de la mayoría de la población le permitirá reservarse los cargos más importantes dentro del municipio en detrimento del resto de los vecinos - pequeños comerciantes, artesanos y agricultores propietarios- con derechos políticos a su ejercicio.

Dos son los principales motivos de fricción originados en el seno de la oligarquía darocense en torno al Concejo. El primero viene derivado del intento por algunos ciudadanos de acceder a la condición de hidalgos sin renunciar a su participación en la política local. Ello sólo se revelará posible si consentían en participar, como los vecinos pecheros, en las cargas fiscales, para lo que debían renunciar a la exención de éstas que sus privilegios les otorgaban.

En segundo término, tienen lugar una serie de pleitos de particulares para conseguir formar parte de la minoría dirigente. Esta tirantez es resultado de un procedimiento de acceso - la fabeación-en exceso rígido. Su poca flexibilidad llevará a algunas personas a solicitar a su Majestad su influencia para participar en los puestos de mayor poder y prestigio dentro del Concejo. El mismo municipio recurre cada vez con mayor frecuencia al rey para que envíe un delegado que asuma la tarea de realizar la «matrícula e insaculación de los oficios".

Al margen de la insaculación de oficios, estos enviados ejercerán una influencia todavía mayor al aprovechar el Concejo su condición de juristas para confiarles la revisión de las Ordinaciones de la ciudad. Las sucesivas síntesis de éstas - 1557, 1577, 1588, 1595- les permitirán introducir modificaciones en los métodos de elección de cargos, en los requisitos que debían cumplir y en las atribuciones que se les conferían. Estos cambios irán encaminados a garantizar la reserva de los puestos decisorios a un sector cada vez más restringido de la población.

Este progresivo carácter oligárquico se manifiesta en medidas como la designación automática para ocupar puestos entre oficiales municipales del año anterior o la fijación de unos límites de edad y unos nivles de riqueza para acceder a los cargos de mayor relieve: Justicia, juez, almotacén, jurados... El antiguo estatuto que permitía el libre acceso a la condición de jurado a todo ciudadano que presentase su caballo y armas el día de San Martír será suprimido. La consecución y desempeño de cargos se caracterizan como un "cursus honorum», un ascenso progresivo de posiciones dentro del Concejo según el grado de poder adquirido. 
La representación política de los vecinos de la ciudad se verá cada vez más mermada. Así lo demuestra el que para garantizar una mínima asistencia a los Concejos generales se crea un cuerpo específico formado por seis oficiales salientes del año anterior. Es evidente que buena parte de los vecinos se excluyen de participar en la vida municipal al hallarse cada vez más en desacuerdo con los objetivos de la minoría dirigente.

El proceso de cerrazón interna dentro del Concejo darocense favorece que la intervención real en los procedimientos de insaculación continúe. Moderada durante las primeras décadas del siglo XVII, se acrecentará a partir de los problemas que tiene la monarquía para el pago del servicio de 1626 , los cuales parecen convencer a ésta de la necesidad de instalar en los municipios que se han demostrado contrarios al voto del servicio una minoría adicta por cuanto le es deudora de sus puestos.

Esta mayor injerencia de la monarquía halla sus cauces en la presentación ante éste de solicitudes, firmadas por su Majestad, el virrey o gobernador del reino para insacular a particulares, así como de habilitaciones y dispensas que les permitiesen acceder a los oficios de la ciudad pese a no cumplir todos los requisitos. Estas peticiones se sucederán en orden creciente hasta constituir un auténtico torrente en la década de los cuarenta, cuando la monarquía debe hacer frente a la vez a los levantamientos portugués y catalán. El recurso a las insaculaciones y habilitaciones se revela una constante durante la segunda mitad del siglo XVII. Prosigue, por supuesto, la acometida de los procesos de infanzonía.

Ei resultado de este proceso ${ }^{4}$ supone, ya a mediados del siglo XVII, una auténtica renovación de la minoría dirigente, que, en lo que resta de centuria, girará en torno a contadas familias: Marco, Orera, de la Cueva, Diz de Aux, Ezpeleta Capdevilla... Las Ordinaciones de 1636 y 1647 no vendrán sino a confirman esta dinámica el incrementar todavía más la importancia de la Hacienda de la que se debe disponer para acceder a los principales cargos.

Esta serie de circunstancias origina que el desempeño de los cargos públicos pase a ser concebido cada vez más por la oligarquía como una fuente más de prestigio --como la propiedad de la tierra o los títulos de infanzonía-, de influencia en el marco ciudadano y a veces, de beneficios. El aumento del número de cargos municipales designados mediante nominación directa permite beneficiar a parientes, clientes o amigos. En general, se percibe una menor preocupación por la función pública por parte de la oligarquía, como manifiestan las frecuentes inhabilitaciones y

4 Para más detalles, véase mi artículo «El Concejo darocense durante el último cuarto del siglo xvl: tendencias de una oligarquía», Jerónimo Zurita. Zaragoza, 1992, 65-66, (1994), págs. 7-13. 
renuncias de aspirantes por no haberse presentado para ser extractos en los cargos en que estaban inseculados, o por vivir fuera de la ciudad.

Las consecuencias de este proceso en la gestión de los recursos de la ciudad serán importantes. Frente a la crisis del siglo XVII, la oligarquía impondrá una administración cada vez más austera que no ocasione mayores cargas a la debilitada Hacienda municipal. Estos objetivos se conseguirán a costa no sólo de aumentar las cargas fiscales, sino de marginar toda una política de abastos y un uso de las Suertes comunales que se había venido desarrollando en el siglo xVI en beneficio de los sectores menos favorecidos de la ciudad.

Para asegurarse el desarrollo de las directrices y también como consecuencia de la misma crisis, la gestión de los bienes de propios será controlada de manera más directa por la oligarquía. Ello, al margen de permitir ocasionales malversaciones por ésta, implicará también un descenso de la capacidad de control sobre los bienes de propios ejercida desde antaño por menestrales y labradores, quienes ven sus necesidades cada vez menos atendidas en un período en que las condiciones de su existencia experimentan un evidente y progresivo deterioro. Estas líneas generales de una gestión severa serán retomadas por los censalistas una vez que asumen en 1673 el control y gestión de los bienes de propios.

Frente a estas actuaciones del Concejo, el descontento de buena parte de población se traducirá en resistencia y falta de colaboración para con aquellas decisiones municipales que los vecinos de la ciudad consideren lesivas para con sus intereses: repartos de trigo, pago de deudas o impuestos indirectos... Las transacciones se sustraerán cada vez más de la regulación municipal y proliferarán los intercambios fraudulentos. En momentos concretos, casos constatados de mala gestión de bienes de propios por parte de miembros de la oligarquía se ven castigados por ataques contra la propiedad particular de éstos.

\section{BIENES DE PROPIOS Y TIERRAS COMUNALES EN DAROCA DURANTE LOS SIGLOS XVI Y XVII: UNA CARACTERIZACIÓN}

En Daroca los bienes de propios ${ }^{5}$ ligados a la Hacienda municipal están compuestos en primer lugar por una serie de propiedades urbanas y

\footnotetext{
5 Para una mejor comprensión de este término, véase BERMúdEZ AZNAR, A., «Bienes concejiles de propios en la Castilla bajomedieval», en Actas del III Symposium sobre Historia de la Administración española. Madrid, Instituto de Estudios Administrativos, 1974, págs. 825-865.
} 
rústicas -éstas últimas en constante crecimiento a lo largo del XVI por la expansión agrícola- sujetas a treudo perpetuo cobrado de forma anual por el Concejo. En segundo término, por una serie de monopolios sobre el abasto y derechos de corretaje que conformaban junto con las sisas o impuestos indirectos sobre objetos de consumo la parte más sustancial de los ingresos municipales. Por último, los cánones pagados por el disfrute de las Suertes comunales, el cobro de las multas - cuyos derechos específicos de percepción se arrendaban con frecuencia- y el arriendo de usos determinados sobre algunos terrenos bajo jurisdicción municipal terminaban por configurar los recursos del concejo.

El tránsito al siglo xVII supondrá, junto a una administración más severa, un aumento de los arbitrios destinados a obtener dinero. Se llevará a cabo un inventario de las tierras vinculadas al municipio para delimitar las obligaciones de sus detentadores. Se crean nuevos monopolios de venta - sobre el carbón, hierro, nieve, tabaco, aguardiente, jabón- que el Concejo entrega en arriendo a particulares. Al lado de las sisas reales, destinadas a pagar los servicios en dinero a la monarquía, el municipio impondrá otras, las denominadas sisas vecinales, orientadas en exclusiva a descargar de censales la debilitada Hacienda municipal.

Los bienes de disfrute comunal a disposición de los darocenses venían condicionados por un lado, por su condición de vecinos de la ciudad, que les facultaba para el uso de las Suertes y la dehesa denominada de los yermos, reservada por un privilegio del rey Juan en 1433 a los vecinos de Daroca y destinada al pasto del ganado vacuno para mejor aprovechar así su población de carrascas y rebollos. Por el otro, por las relaciones establecidas con la Comunidad de aldeas, una unidad jurídico-administrativa mucho más extensa que abarcaba a gran número de lugares y disponía de sus específicos bienes de propios y tierras comunales, de disfrute colectivo por todos sus miembros integrantes.

Estas relaciones, siempre tensas, marcarán distintos acuerdos respecto al aprovechamiento ganadero ${ }^{6}$. En primer lugar, se permitía el acceso tanto a los comunales de la ciudad como a los de la Comunidad a aquellas vecinos de Daroca o habitantes de las aldeas que poseyesen casas o heredades en el otro ámbito de jurisdicción, siempre y cuando residiesen en él un mínimo de dos meses al año. En segundo término, todos los vecinos de Daroca tenían determinados derechos de pasto compartidos con la

6 Véase Archivo Municipal de Daroca (AMD), Estatutos de la ciudad, (10.7.1), Concordias de 1449,1540 y 1585 . 
Comunidad en una serie de comunales -Monteagudo, Aldehuela, Olmedilla - situados en las proximidades de Daroca. Tanto habitantes de la Comunidad como vecinos de Daroca tenían libre acceso para llevar a pastar sus ganados a las heredades en barbecho entre los meses de septiembre y marzo. En el caso de las viñas, el permiso de pasto se retrasaba hasta una vez efectuada la vendimia.

Una situación especial viene constituida por los vecinos de los lugares colindantes, dado que muchos de ellos disponen de heredades dentro del término de Daroca que podían destinar a usos ganaderos. A éstos, la ciudad les facultaba para usar la alera foral y pacer sus reses en los montes - no en las viñas - sitos en los términos de Daroca con que confrontaba cada lugar respectivo, así como en las viñas y rebollares de su propiedad. Se les negaba, sin embargo, el derecho a llevar a pacer su ganado tanto en las viñas de monte o vega que no les pertenenciesen como en la dehesa comunal.

Las concordias entre la ciudad y Comunidad de aldeas surgidas en torno a discusiones sobre el uso y delimitación de dehesas comunales, los derechos de la alera foral o los ataques del ganado a las heredades labradas, nos informan de un deterioro progresivo a lo largo del siglo XVI en ambas jurisdicciones de los lugares destinados a pasto y provisión de leña como consecuencia de un uso continuado e intensivo por parte de particulares. En la Comunidad ${ }^{7}$ deberá señalarse como factor adicional para su degradación la presencia de las reses de la Casa de ganaderos de Zaragoza y la extracción de leña con destino a la capital del reino.

Estas apreciaciones condicionan en el caso de Daroca que el Concejo lleve a cabo, ya desde mediados del siglo XVI, una serie de disposiciones restrictivas del uso ganadero del suelo ${ }^{8}$. En 1546 al observarse que una vigilancia deficiente es la causa de «los montes y termino de Daroca estar muy disminuidos y desipados, y los arboles fructiferos estar muy perdidos», el Concejo impide a los vecinos el tener cabras en los términos de la ciudad,

7 Al respecto, ya a fines del siglo XVIII afirmaba Asso que «el partido de Daroca y señaladamente el territorio de Paniza, Aladrén, Segura y la Cuerla estuvo en otro tiempo muy bien provisto de carrascales, pinares y montes de leña. Mas éstos se hallan hoy en dia muy deteriorados y amenazando su última ruina por la impericia de los carboneros, por el excesivo consumo de carbón que se hace en Zaragoza y por la inobservancia de los Estatutos antiguos de la Comunidad, renovados en 1686, que prescriben las más acertadas reglas para el reparo y conservación de los montes» Véase Asso, I., Historia de la economía política de Aragón. Zaragoza, Guara, 1983, pág. 91 .

8 Véase AMD, Estatutos de la ciudad, (10.7.1), Estatutos de los años 1546, 1573 y 1574. Véase también Act Mun, 1534, 22 de marzo, 1553, 11 de nov., 1557, 23 de abril, 1604, 9 abril. 
medida ya aplicada en 1534. En 1553 el perjuicio que ocasionan los ganados menudos obliga al municipio a restringir la construcción de corrales y parideras. En 1557 se prohibe dejar a los animales pacer solos de noche, dado que «se destruye todo el término». En 1573, en fin, para proteger las heredades - sobre todo las existentes en la vega-, se impedirá la presencia de todo ganado vacuno de marzo a junio en el término municipal.

Las mismas disposiciones se empiezan a tomar respecto a la leña de las tierras comunales ${ }^{9}$. Si en la primera mitad de siglo el municipio sólo proclama prohibiciones parciales de recoger leña -1529, 1533- y concede con frecuencia permisos a particulares para recoger aliagas, a partir de mediados del XVI las medidas tienden a endurecerse. Las disposiciones aprobadas en 1553 al constatar el daño hecho en los términos de la ciudad «en hazer lenya, aliagas, tomillos, salvias, rebollos» son complementadas en 1559 por un estatuto más específico «contra los que sacan leña de la dehesa, así escalando, rompiendo, labrando, como cortando y talando». En las Ordenanzas de 1595 el veto se hace extensible a la recogida de leña para las tintorerías, ollerías, tejerías y cañerías en montes y lindes de heredades. Desde fines del siglo XVI y durante todo el siglo XVII, la protección del aprovechamiento de la dehesa se traduce en numerosas proclamas de vedas que impiden recoger bellotas y leña en la misma.

Por supuesto, la reiteración de estas disposiciones da cuenta no sólo del interés del Concejo por evitar una total degradación de heredades y dehesa, sino también de su incumplimiento reiterado como resultado de la presión del hombre sobre el medio. Esta circunstancia provoca que la labor de viñadero o guarda de heredades sea cada vez más peligrosa, razón por la cual desde mediados de siglo se hará cada vez más difícil hallar labradores dispuestos a ser insaculados para ocupar este cargo.

En este sentido ${ }^{10}$, la decisión tomada por el Concejo respecto a la dehesa boyal y las propiedades particulares será semejante. A partir de 1568 establecerá un guarda asalariado fijo responsable de protección de la dehesa. A fines del XVI se abandona el método establecido desde antiguo por la costumbre para elegir a los viñaderos o vigilantes de las parcelas pri-

\footnotetext{
9 Véase AMD, Act Mun, 1529, 7 de enero, 1553, 11 de nov., 1560, 4 de feb., 14 de abril, 1564, 28 de enero, 161619 de feb. Véase también AMD, Ordenanzas de 1588, (13.3.6), Ord. 59.

10 Véase AMD, Act Mun, 1548, 5 de agosto, 1549, 27 de dic., 1550, 27 de dic., 1568, 19 de feb., 29 de oct., 24 de dic., 1576, 15 de enero, 19 de feb., 1582, 14 de enero, 1584, 14 de enero, 1591, 22 de enero, 1593, fol. 4r stes, 1596, 13 de enero, 1597, 11 de enero, 1600, 9 y 28 de enero, 1611, 7 y 8 de enero, 1613, 6 de enero, 1616, 2 de enero, 1620, 19 de enero, 1623, 4 de enero.
} 
vadas situadas en el término municipal, divididas en sectores -el Prado, Vallantigo, los Huertos, Ancho, Xalagra, el Val y Luco- para su control. En vez de ser sorteados los puestos entre los labradores, serán nombrados de manera directa por el Concejo. Esta medida entraña que se abandona el matiz comunal existente en el cargo en aras de un mayor control y vinculación al municipio. El viñadero contará con un salario sufragado por los dueños de las parcelas mediante el pago de un canon fijo — viñadería- al Concejo por yubada en el secano o hanegada en la vega.

La actuación del Concejo en el siglo XVII viene determinada por estas líneas iniciales, confirmadas por las Ordinaciones de la ciudad de los años 1636 y 1647. Como novedad, se introduce desde fines del xvı una mayor preocupación por regular los derechos de caza en la dehesa y los términos de la ciudad. El abandono de tierras que se percibe en la segunda mitad del XVII también ocasiona que usos ganaderos y de caza se extiendan a tierras en barbecho antes labradas e incluso a tierras que todavía se cultivan próximas a éstas. Es en este período cuando más proliferan los mandatos contra cazadores, perros y bueyes que ocasionan perjuicios en el trigo de las eras.

La atenuación de los años de carestía durante la segunda mitad de siglo no parece hacer descender las presiones de los vecinos de la ciudad sobre las tierras de la dehesa. La obligatoriedad impuesta al guarda de manifestar al Concejo las relaciones de multados y su causa nos ha permitido caracterizar a los acusados. La introducción ilícita de ganado en la dehesa es protagonizada por vecinos de los lugares aledaños. El abuso en los derechos de caza abarca a un espectro amplio de la población de Daroca que incluye a clérigos ni hidalgos. Las numerosas vedas establecidas sobre la recogida de leña, bellotas y aliagas son burladas por criados de ciudadanos y clérigos, por mozos de los lugares vecinos $\mathrm{y}$, sobre todo en años de carestía, por gran número de muchachos y mujeres que parecen hallarse entre los estratos más humildes de la ciudad.

\section{LAS SUERTES COMUNALES DE DAROCA}

\subsection{El origen de las Suertes Comunales: la expansión del siglo XVI}

El origen de las Suertes comunales parece proceder de unas determinadas tierras sitas en la dehesa comunal que se acotan a fines del siglo $x \mathrm{~V}^{11}$.

11 Compárese con el reparto efectuado por el concejo por estas mismas fechas en González Jiménez, M., El Concejo de Carmona a fines de la Edad Media (1464-1523). Sevilla, Diputación Provincial, 1973, págs. 104-107 y 201-210. 
De ahí su denominación de «Suertes de la defessa» en las Actas municipales que hace suponer su entrega por sorteo. En 1484 se establece en un "tiempo de tretze anyos» la duración de su usufructo a cambio del pago a la ciudad de una cantidad anual en dinero calificada de "tribut». Su número oscilará durante la última década del siglo xv entre 60 y 67 . Por el dominio útil se entregaba un canon que se reducirá de dieciséis a doce sueldos, lo que nos permite suponer que el aumento de su número venía condicionado por una reducción en su extensión que implicaba la reducción del canon ${ }^{12}$.

El cambio de su pago en dinero a la contribución en especie ${ }^{13}$ pagada ya en la segunda década del siglo XV 1 -1518- quizás esté vinculado con el cese del cobro por el municipio de contribuciones por parroquias; pero de manera indudable se halla en relación con la configuración de un Pósito, la Cámara del Trigo, que necesita fuentes de suministro cada vez más estables y seguras. Las tierras repartidas proveerán los denominados "cien cahices de trigo de las Suertes", tal y como nos aparecen ya en las Ordinaciones de 1566. Esta cantidad se mantendrá invariable durante todo el siglo XVI y buena parte del XVII.

El carácter comunal de estos terrenos se plasma de la forma manifiesta en su vínculo, bien reflejado en las Actas municipales a fines del primer cuarto del siglo XVI, con la estructura parroquial de la ciudad ${ }^{14}$. Sujeta su forma de distribución a algunas vacilaciones durante la primera mitad del siglo XVI, 1551 consagra la vuelta al método fijado por la costumbre: el reparto por parroquias, sorteadas en 1553 para San Blas. El período de donación era de once años, con un pago anual total de cien cahíces, con la excepción del sexto año, que se otorgaba en barbecho para que la tierra descansara y la ciudad no recaudaba canon alguno ${ }^{15}$.

Era misión del cambrero el asegurar a la administración del Pósito el cobro de estas cantidades de grano y su disposición por la Cámara ya en el mes de enero, cosa que resultaba siempre difícil cuando la coyuntura agrícola se tornaba adversa. El municipio podía conceder oratorias en el pago o auténticas reducciones del mismo, como sucede en 1550. Su fijación era encomendada entonces a diputados nombrados por el Concejo. Se intentaba por lo general que la pérdida de rentas por la ciudad, si bien asumida, fuese lo más pequeña posible. Su adeudamiento se podía reco-

\footnotetext{
Véase AMD, Act Mun, 1484, 1485, 1488 y 1489, “Receptas del procurador general».

Véase AMD, Act Mun, 1518, rendición de cuentas de la Cámara y 1566, 27 de dic.

Véase AMD, Act Mun, 1524, 4 de marzo y 1525, 10 de marzo.

Véase AMD, Act Mun, 1551, 7 de junio, 5 y 12 de julio, 1553, 5 de mayo.
} 
nocer mediante comandas, como las testificadas en 1562 por el notario Pedro Agudo ${ }^{16}$.

Las Ordinaciones de 1566 relativas al trigo de las Suertes nos informan de su modo de preservación y las condiciones de su uso. Los cahíces procedentes de las Suertes debían guardarse en el granero del Pósito siempre apartados, no se podían prestar ni vender hasta recaudarse en su totalidad y el producto de su beneficio tenía que emplearse en luir censales. Como sucedía con la maquila cobrada por moler en el molino de la ciudad, el cambrero durante el último cuarto del XVI y principios del XVII retribuía al administrador general de la Hacienda municipal el montante del valor del trigo que la cambra recibía por las Suertes ${ }^{17}$.

En conclusión, el siglo xvı nos ofrece una visión en que el acceso a la propiedad comunal por parte de los vecinos de la ciudad se regula a través de la organización parroquial, con claras connotaciones de carácter comunal también presentes en la utilidad que se pretende dar al trigo recaudado. La ausencia de dificultades en su cobro a lo largo del siglo XVI confirma la avidez de tierra que condiciona su creación. De otro modo sucederá, como enseguida veremos, en la centuria siguiente.

\subsection{El siglo XVII}

A lo largo del siglo XVII las condiciones de acceso a las Suertes comunales sufren serios trastornos. Esta serie de cambios viene unidos al muy probable descenso de los rendimientos de la tierra, a la gestión más severa que el municipio asume en el siglo xvIl y a la oposición que va suscitando sus medidas entre amplios estratos de la población que se sienten menos protegidos por el Concejo de lo que lo habían estado en el siglo $x \vee$. La resistencia al pago de los treudos será una de las manifestaciones más palpables de esta oposición.

Ya desde sus inicios, el siglo xvli ve alumbrar nuevas propuestas respecto al destino de las Suertes tendentes a su conversión en treudo perpetuo. La resolución quedará reducida a un sustancial aumento del período de duración de su arrendamiento. Al parecer, los motivos de esta decisión están relacionados con el interés del municipio por facilitar el cobro del treudo al asegurar a su usufructuario una tenencia prolongada

16 Véase para todas estas cuestiones AMD, Act Mun, 1550, 12 de enero y 17 de agosto, 1560,29 de julio y 18 de agosto, 1563,5 de marzo.

17 Véase AMD, Act Mun, 1566, 8 y 11 de nov., 27 de dic., 1576, 4 de marzo, 1584, 31 de marzo, 1596, 3 de mayo, 1606, 24 de marzo. 
de la tierra. Las duras condiciones de disfrute, sin embargo, motivarán intentos de renuncia que son anulados por el Concejo ${ }^{18}$.

En concreto, la capitulación acordada en agosto de 1604 distribuía por orden numérico las Suertes entre las parroquias de la ciudad, en cuyo seno eran sorteadas. A cada Suerte, según su extensión y calidad, se le atribuía un canon, que oscilaba entre el cahíz y medio y los dos cahíces con una fanega. El parroquiano a quien le correspondiese debía contraer la obligación de su pago anual por un período de veintinueve años, amén de comprometerse a plantar y mantener «falces» para separar con nitidez sus parcelas de las colindantes y a limpiar la acequia madre cada tres años. Las Suertes se podían rearrendar por parte de su tenente, pero éste debía contar para ello con la aprobación del municipio.

Las condiciones del siguiente arrendamiento, en el año 1634, marcan una diferencia notoria con respecto al anterior. Repartidas entre las parroquias, son sorteadas entre sus miembros bajo la supervisión de una persona nombrada por el concejo. Fijado en un principio su período de tenencia en diez años, las cláusulas finales del arrendamiento los reducen a seis. Se acordaba, asimismo, que quien tuviese una Suerte durante este tiempo ya no se le podía obligar a que la trabajase de nuevo, salvo si consentía de forma voluntaria. A su muerte, podía renunciar a ella su heredero y ser de nuevo sorteada, como de hecho ocurre ${ }^{19}$. Los hidalgos o caballeros tenían, ya desde un principio, opción a su rechazo.

Los posteriores sorteos ${ }^{20}$ de las tierras comunales confirman esta tendencia. Se sucederán de seis en seis años -1640, 1646, 1652, 1658, 1664...-; pero con una variación sustancial: ya no se repartirán por parroquias, sino entre todos los vecinos de la ciudad unidos en una sola bolsa, posibilidad ya planteada en 1634 y descartada. A partir de 1646 se concederá el primer año de los seis de barbecho, esto es, libre del pago de canon. Desde 1658 se precisará que, caso de morir su poseedor y su heredero no desearla, éste deberá devolver la Suerte dentro del mismo año a la ciudad. Se observa, por tanto, una suavización de las condiciones de tenencia de estas parcelas.

\footnotetext{
18 Véase AMD, Act Mun, 1604, 25 de junio, 16 y 30 de julio, 10, 20 y 28 de agosto, 3 de sept. y 19 de nov.

19 Véase AMD, Act Mun, 1634, 18 de agosto, 26 de oct., 1635, 6 de oct., 1642, 5 de sept., 268 de nov., 1651, 18 de agosto, 1659,20 de junio, 22 de agosto y 2 de sept.

20 Véase AMD, Act Mun, 1634, 17 de marzo y 7 de julio, 1640, 23 de marzo y 6 de mayo, 1646, 3 de abril, 1652, 12 de mayo, 1658, 3 de mayo, 7 y 8 de junio, 13 de sept., 1 de oct., 1664, 3,14 y 22 de junio.
} 
Esta serie de concesiones parecen indicar una menor atracción por el cultivo de las tierras en un momento en que el mercado de grano sufre una contracción evidente, al descender la población - y con ella la demanda de trigo- y crecer las cargas fiscales. Las precisiones de que quien cultivase una Suerte por un período de seis años no se le puede obligar a tomarla implica dificultades a la hora de hallar cultivadores que podrían explicar la mayor presencia del municipio en los repartos.

Este menor deseo por el cultivo de la tierra aparece también avalado por las mayores dificultades que, conforme avanzamos a lo largo del siglo XVII, plantea la cobranza del trigo. Si en un primer momento éstas vienen motivadas por la práctica de rearrendar ${ }^{21}$ el dominio útil que dificulta la localización del treudero, pronto se convertirán en auténticas resistencias al pago que alcanzan su cénit durante los años treinta y cuarenta. Motivadas tanto por los rendimientos decrecientes como por el mayor grado de endeudamiento del campesino, los problemas crecen en aquellos años que las malas cosechas encarecen el valor del trigo. En este período se comienza a dar el caso, más tarde experiencia cotidiana, de que pese a iniciarse el cobro del trigo con la recogida de la cosecha todavía no se había satisfecho del todo en marzo del año siguiente ${ }^{22}$.

Como expresión de estas dificultades, a partir de 1632 comienzan a aparecer en la contabilidad municipal las relaciones de deudores. En 1642 el Concejo se ve obligado a enviar a los jurados para percibir el canon. Al año siguiente, apalabrará con un particular su cobro con la obligación taxativa de que empiece su tarea en agosto. Algunos vecinos, endeudados, prueban por un tiempo la carcel. Otros, si consiguen librarse de ella e incluso prorrogas en el pago, es gracias a la entrega de fianzas. Para evitar todas estas complicaciones, el municipio introducirá desde 1651 la práctica del cobro del trigo recién segado en las eras, que se perpetuará en la segunda mitad de la centuria.

Los problemas endémicos de cobro de deudas se ven agravados en esta segunda mitad por la tendencia al abandono de las Suertes por sus detentadores - $1660,1663,1674,1687-{ }^{23}$, conforme su cultivo deja de

\footnotetext{
21 Véase AMD, Act Mun, 1606, 28 de julio, 1609, 1 de mayo, 1613, 12 de julio, 1617, 14 de julio, 1634,20 de enero y 1636, 16 de marzo.

22 Véase AMD, Act Mun, 1631, 5 de dic., 1632, 23 de enero y 29 de oci., 1637, 20 de feb., 1640, 1 de marzo, 1641,15 de feb. y 30 de marzo, 1642, 24 de enero y 14 de marzo, 1644,1 de abril, 1646,6 de abri.

23 Véase AMD, Act Mun, 1660, 5 y 12 de marzo, 2 de abril, 1663, 13 de abril, 20 de julio, 1674,20 de abril, 1687, 21 de marzo.
} 
ser considerado rentable. El municipio debe conminar de manera reiterada a los dueños a que las cultiven ${ }^{24}$, con la intención no sólo de cobrar una renta sino de obligar al tenente a mantener una actitud de constancia y responsabilidad hacia estas parcelas.

Esta situación general abre cauce a la idea de la cesión a treudo perpetuo de las tierras comunales como criterio más rentable de explotación. Al margen de recoger la idea de perpetuación ya planteada a principios de siglo que tanto debía interesar a muchos labradores, también satisface las aspiraciones de algunos ciudadanos que, ante el deterioro del sistema crediticio, buscan en la tierra nuevos cauces de inversión. Por último, regula de manera definitiva las condiciones de acceso a las Suertes en un momento de incertidumbre. No es casual que las decisiones relativas a estas tierras comunales se lleven a cabo en los años comprendidos entre la definitiva bancarrota de la Hacienda municipal y la aprensión de los bienes de propios por los censalistas.

Así en 1668 el municipio aprueba la decisión ${ }^{25}$ de transformar el prado de la ciudad en doce Suertes de diez fanegas de extensión cada una. Serán las denominadas "Suertes Nuevas» que se ofrecen a treudo "dandoles dos años de barbecho por el trabajo de rompellas" a los que de forma voluntaria se presenten para su sorteo. Ante el "poco calor» que suscita entre los vecinos la oferta en una época de abandono de tierras, el Justicia, en atención a la demanda de muchos particulares, propone al Concejo cederlas por un treudo perpetuo de dos cahíces y una media de trigo anuales por Suerte, a lo que éste acepta. El sorteo se realiza de inmediato entre los aspirantes. Los doce agraciados por el sorteo resultan ser seis labradores, dos nobles, dos notarios y otros dos ciudadanos integrados en la oligarquía de Daroca.

El mismo camino hacia la perpetuación seguirán, en medio de un creciente interés, las Suertes Viejas en mayo de 1670, con la excepción de las once o doce parcelas de peor calidad, que se destinarán a prado. Las

24 Este hecho, en principio, conformaría la opinión de Bernal de que «los repartos del siglo xv y xvII tuvieron extrema fragilidad en cuanto a la permanencia de la explotación de las suertes repartidas» y que los repartos y abandonos de Suertes seguían «ritmos muy próximos a la evolución de la coyuntura demográfica y económica». Sin embargo, debo matizar que los problemas de cultivo existentes con las Suertes en Daroca anteceden a su entrega bajo treudo perpetuo y que el municipio desarrolla, por lo general con éxito, un papel regulador y unas medidas de compulsión que obligarán al cultivo de las Suertes y el pago de los cánones. Véase BERNAL, A.M., "Haciendas locales y tierras de propios...", pág. 290.

25 Véase AMD, Act Mun, 1668, 8 y 27 de enero, 26 de feb, 1669, 22 de nov., 1670, 2, 9 y 18 de mayo, $1670,2,9$ y 18 de mayo, 1673,6 de oct., 1687,21 de marzo. 
48 restantes se sortearán entre los vecinos de las ciudad con pregón público y un mayor margen de tiempo del que tuvieron las Suertes Nuevas. Si el valor del treudo se fija en mayo, el sorteo se efectua en diciembre. Entre sus beneficiarios no se observa una presencia especial de la oligarquía. Al ser el treudo perpetuo no finaliza con la muerte del usufructuario, sino que el dominio útil es transmisible a sus herederos, quienes pueden disponer de ella mientras sigan pagando el treudo.

Sin embargo, las cantidades de trigo cobradas por el uso de las Suertes serán pronto protestadas por los usufructurarios al considerarse excesivas. Ya en octubre de 1673 varios particulares se quejan ante el Concejo del "poco provecho y mucho gasto" que ocasionan las Suertes Viejas, dado «que en dichas Suertes ni hai barbecho ni para años de desgracia tienen resciba de piedra, río ni niebla", es decir, deben trabajar las tierras de forma continua para poder pagar. Ante este hecho, suplican que se modere el treudo y se ajuste a la cantidad y calidad de la tierra de cada parcela. La decepción es palpable y, como consecuencia, ya en 1674 se constata que "muchas suertes de la ciudad están sin trabajar».

La percepción por los detentadores de las parcelas, en una época de atonía del mercado de las tierras, de que los cánones exigidos por el municipio resultan altos provocará que las dificultades de éste a la hora de cobrarlos sean notables ${ }^{26}$. Numerosas disposiciones establecen el cobro del trigo en las eras de agosto a noviembre, o penas para los deudores de privación de los oficios de la ciudad y ejecución de sus bienes, como únicos medios para garantizar el pago del treudo. Su percepción solía ser encomendada a colectores.

Los problemas del tenente para cumplir con el pago originan que se den, sobre todo a partir de 1673 , una serie de traspasos de Suertes ${ }^{27}$ que contribuirán a dificultar su cobro. Si bien en principios estos traspasos deben hacerse con el consentimiento del Concejo, algunos se realizan a hurtadillas, con los consiguientes problemas para identificar a la persona que debían asumir su pago. Ante esta situación, el municipio reacciona a veces con medidas drásticas, como comprueba Leandro Marzo al obligar-

\footnotetext{
26 Véase AMD, Act Mun, 1654, 9 de oct., 1655, 9 de abril, 1660, 16 de julio, 1663, 27 de julio y 15 de nov., 1664, 18 de abril, 1671, 12 y 15 de junio, 1672, 1 de julio, 1674, 2 de feb., 1682, 31 de julio, 1687, 22 de agosto y 28 de nov., 1690, 24 de nov., 1693, 25 de sept., 1694, 30 de junio, 27 de agosto, 24 de nov.

27 Véase AMD, Act Mun, 1653, 16 de mayo, 1659, 20 de junio, 1673, 23 de junio, 1679, 19 de mayo, 20 de oct., 1686, 21 de marzo, 1687, 14 de feb. 29 e agosto, 5 de sept., 1592, 21 y 28 de marzo, 11 y 13 de abril, 1694, 26 de feb. y 15 de sept. Para una relación de los tenentes de las Suertes a fines del siglo xvII, véase Act Mun, 1698, 28 de feb.
} 
le el municipio en 1679 a hacerse cargo de la deuda de Clemente Romeo, el anterior detentador, a quien se le había arrendado.

Por lo general, el Concejo concedía la cesión de la Suerte con la condición de que el nuevo detentador del dominio útil reconociese su obligación con la ciudad. Sin embargo, el Concejo podía impedir su traspaso para asegurarse el cobro de canon ${ }^{28}$. Así actúa, por ejemplo, en 1687 con Juan Fox «pues es persona que paga el treudo con mucha puntualidad». La buena calidad de algunas tierras incentiva la codicia de particulares que pretenderán hacerse con ellas: D. Luis de Orera ofrece el caso más claro al pretender ese mismo año de 1687 servirse de la deuda contraída con el municipio por Andrés Millán para arrebatarle el dominio útil de su Suerte, que le había sido cedida por Ana Mateo.

La apropiación de la administración de los bienes de propios por los censalistas en 1673 otorgará la gestión del dominio útil a la Conservaduría ${ }^{29}$, mientras que su cuidado correrá a cargo de la ciudad. Por este motivo, los problemas de transferencia citados son solucionados por el Concejo. Las decisiones de la Junta de Conservadores se ven limitadas por la cesión a treudo perpetuo a asegurar el cobro estricto de los cánones estipulados. En este sentido, resulta muy significativo que al renovarse la concordia entre Concejo y censalistas en 1693 se disponga que los que poseen Suertes «se obliguen de nuevo a la ciudad y el que no fuere persona segura se le quite la suerte».

En resumen, en torno a las Suertes y sus problemas de cobro se originará todo un proceso de remodelación de las tenencias que tenderá a vincularlas a aquellas personas cuya capacidad económica o de trabajo les permita cumplir con el pago de los cánones, resultado de una política más pendiente de la rentabilidad económica que de facilitar un acceso más igualitario a la propiedad comunal. Las consecuencias de estas orientaciones no destacarán de forma inmediata en una época de atonía demográfica y débil presión sobre la tierra como es la segunda mitad del xvII; pero se dejarán sentir en mucha mayor medida en el siglo siguiente al crecer la población e incrementarse la necesidad de tierras. En este sentido, censos de la época confirman la definitiva configuración de un sector amplio de jornaleros en el seno del mismo campesinado.

28 Véase la nota 23.

29 Consúltese al respecto el capítulo número 16 de la concordia acordada en 1673 entre el Concejo y los censalistas que les faculta para administrar los bienes de la ciudad en AMD, Act Mun, 1673, fols.stos. Véase también Act Mun, 1693, 25 de sept. 


\section{CONCLUSIONES}

Como conclusiones, se puede comprobar que la concepción de la gestión de las Suertes y tierras comunales no dejan de coincidir con los esquemas centrales adoptados por la oligarquía durante el siglo XVII al asumir la administración de la ciudad: criterios de mayor austeridad, preocupación por el cobro de las deudas, presencia moderada de los intereses de la oligarquía dirigente, marginación de los estratos de labradores y menestrales en los mecanismos de control y un sacrificio de derechos colectivos y aspectos de interés común para favorecer la conservación de algunos aprovechamientos comunales; pero sobre todo al servicio de una Hacienda más saneada y un aprovechamiento más rentable.

Por tanto, el proceso de creciente oligarquización vivido en el seno del Concejo no parece implicar de manera inmediata ni una mala gestión de los recursos de la ciudad ni decididos ataques contra la propiedad comunal. Pese a su escasa presencia en el Concejo, el limitado poder coactivo del municipio y la importancia concedida a los derechos del común permitirán a los vecinos de Daroca desarrollar una influencia relativa sobre la actividad municipal en unos momentos en que se sienten menos protegidos por ésta. Esta presión, ejercida bien mediante ataques puntuales a la propiedad privada, bien a través de actos de resistencia pasiva, bien por medio de la simple defraudación, marcará durante el siglo XVII la respuesta de los vecinos a la gestión más severa que la oligarquía impone sobre la administración de la ciudad.

Estos hechos, en última instancia, nos llevarían a considerar que la presión de la oligarquía sobre propios y comunales no se ejerce de forma homogénea sobre todo el territorio peninsular. El proceso de privatización de tierras comunales aparece condicionado por aquellos factores que determinan los derechos concretos sobre el suelo de los diferentes estratos sociales, así como la mayor o menor presión de los vecinos en nombre del común. En este sentido, resulta incuestionable la importancia del proceso de conquista de tierras a los musulmanes y repoblación en tanto que establece las bases de partida, sujetas a evolución, de las diversas formas de propiedad de la tierra y las relaciones de producción subsiguientes. Un primer hecho diferencial constatado entre las Coronas de Castilla y Aragón lo constituye el no reconocimiento en esta última a la monarquía del derecho a disponer de los terrenos asimilables por sus características a las "tierras baldías" castellanas, lo que restará a ésta protagonismo en el proceso de privatización de tierras comunales. 
A un nivel más general, las tierras de realengo se revelarían como un territorio más propicio para la defensa de propios comunales gracias a la disposición de una serie de privilegios colectivos que favorece el mantenimiento de vínculos comunes. Las pequeñas ciudades y los nucleos rurales serían las zonas donde los usos comunales - sobre todo los relativos a derechos de pasto - se mantendrían en mayor medida como consecuencia de su importancia en el mundo agrario y de la mayor cohesión de las pequeñas Comunidades, más replegadas en sí mismas. Las grandes ciudades, por el contrario, configuran un espacio social más abierto, resultado de su mayor peso poblacional, el menor control social, la mayor variedad y complejidad de actividades económicas y relaciones sociales. Estas circunstancias entrañan un menor apego entre sus habitantes a las prácticas comunales, más al uso en el mundo agrario.

Por este motivo, la gran ciudad puede convertirse en un entorno propicio para que se den formas decididas de vinculación por parte de la oligarquía de tierras comunales y bienes de propios, como es el caso de Sevilla ${ }^{30}$. La enajenación de estas tierras hallaría una mayor resistencia en núcleos pequeños, sobre todo, si como sucede en Daroca, su identidad de tierra de realengo se ve reforzada por derechos privativos y fueros de frontera. Caso de darse, el proceso de patrimonialización parece ser más lento y apoyarse en mayor medida en circunstancias favorables, como el descenso demográfico - que reduce la presión sobre la tierra- o el grado de endeudamiento de la Hacienda municipal ${ }^{31}$. La mayor tradición comunal y ia presión de los vecinos permitirá, de igual modo, a través de los repartos de suertes a cambio de un canon, el acceso a la tenencia individualizada por sectores más amplios de la población.

so Véase Martinez Ruiz, J.I., Finanzas municipales y crédito público en la España Moderna. La hacienda de la ciudad de Sevilla, 1528-1768. Sevilla, Ayuntamiento, 1982, págs. 231-262.

31 Sobre la importancia de estos factores, véase GARcía SANZ, A., "Bienes y derechos comunales..." y BERNAL, A.M., "Haciendas locales y tierras de propios...", págs. 287-291. 


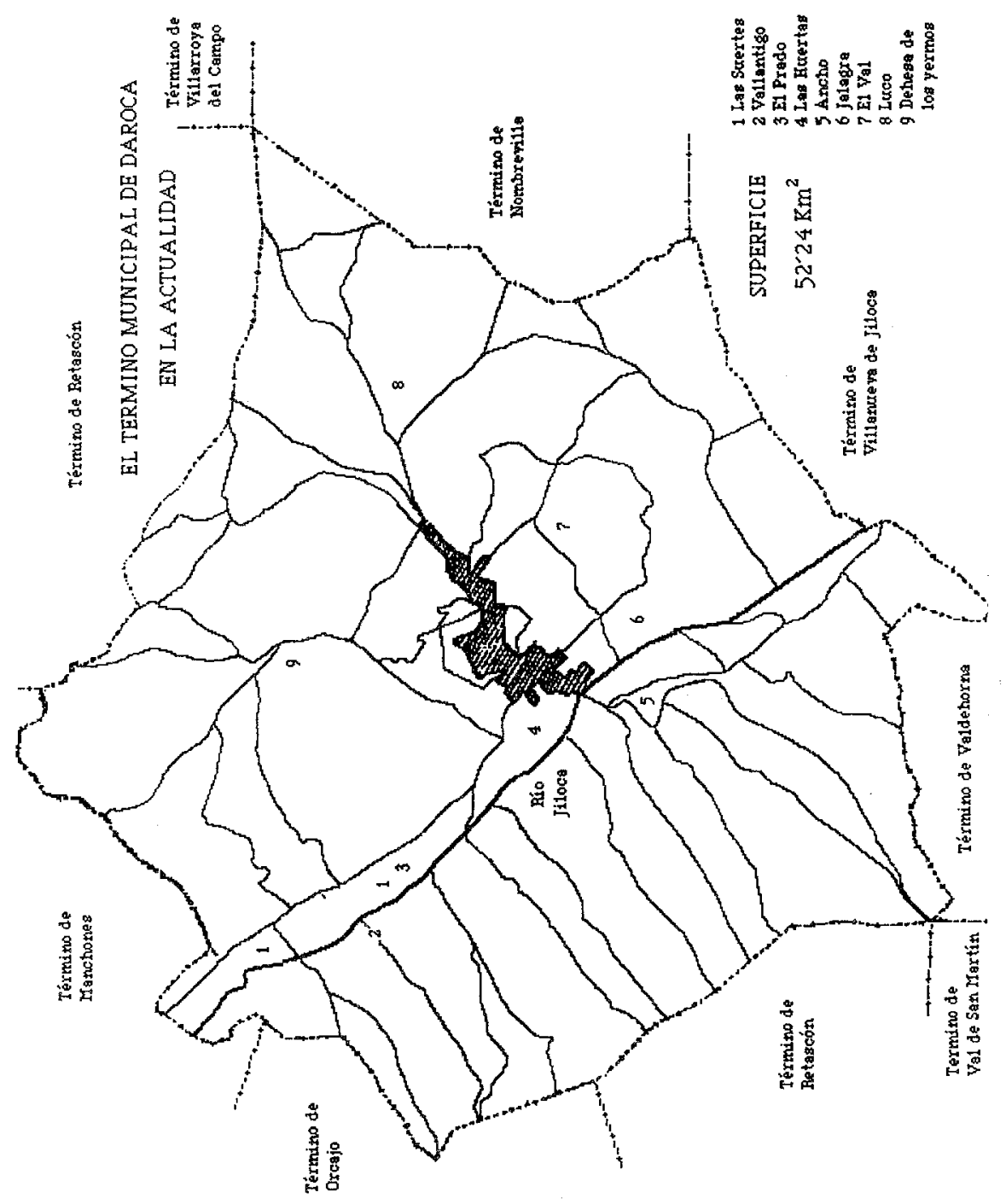

